\title{
NOTE
}

\section{Transformation of chlorophyll a during viral infection of Emiliania huxleyi}

\author{
Nicole J. Bale ${ }^{1,2, *}$, Ruth L. Airs ${ }^{1}$, Susan A. Kimmance ${ }^{1}$, Carole A. Llewellyn ${ }^{1}$ \\ ${ }^{1}$ Plymouth Marine Laboratory, Prospect Place, The Hoe, Plymouth PL1 3DH, UK \\ ${ }^{2}$ Present address: Royal Netherlands Institute for Sea Research (NIOZ), 1797 SZ, Den Hoorn, The Netherlands
}

\begin{abstract}
Although viruses can significantly reduce primary production-mediated carbon cycling, the effect of viral infection on the principal photosynthetic pigment that enables autotrophic production, chlorophyll a (chl a), remains unresolved. We compared the production of chl a transformation compounds in Emiliania huxleyi cultures undergoing viral infection with that in control cultures left to decline in the stationary phase of growth. A high performance liquid chromatography mass spectrometry method developed for the detection of Type I chl a transformation products was used. A rapid decline in cellular concentrations of chl $a, \mathrm{C}-13^{2}$ diastereomer of chl $a$ (chl $a^{\prime}$ ) and phaeophytin a (phytin a) was observed in both infected and control cultures. The most notable finding was the significant increase in the cellular concentrations of Type I chl oxidation products (allomers) in the infected cultures, and we hypothesise that this may be due to increased oxidative stress and reactive oxygen species.
\end{abstract}

KEY WORDS: Viral infection - Emiliania huxleyi - Chlorophyll a - Transformation products · Oxidative transformation

\section{INTRODUCTION}

Over the last 2 decades, research has revealed that marine viruses substantially affect phytoplankton bloom dynamics (Bratbak et al. 1993, Baudoux et al. 2006, Short 2012). In addition to a direct reduction in total cell abundance, the species-specific nature of viruses leads to the regulation of interspecies competition and succession within a mixed phytoplankton community (Brussaard 2004). Viral lysis of phytoplankton also performs a central function in the cycling of marine organic matter into the microbial loop: it results in the release of cell constituents as dissolved organic matter and replicated viruses (Bratbak et al. 1993, C. Lønborg pers. comm.). Although viruses can significantly reduce primary production mediated carbon cycling (Suttle 2005), the effect of viral infection on the principal photosynthetic pigment that enables autotrophic production, chlorophyll $a(\mathrm{chl} a)$, remains unresolved. A previous study that focused on the response of pigments during viral infection of Emiliania huxleyi (Llewellyn et al. 2007) noted that as chl a disappeared, Type I chl $a$ transformation products such as chlorophyllide $a_{\text {, }}$ phaeophytin a (phytin a) and phaeophorbide a were not detected, and it was surmised that chl a degradation during viral infection proceeded via disruption of the cyclic tetrapyrrole system. In the present study, we examined the chlorophyll transformation during viral infection in more detail. Our experiment was designed so that infection occurred during the stationary phase rather than during exponential growth to ensure that the control and infected cultures were in the same growth phase. This allowed for a direct 
comparison of chl a transformation during viral infection and during non-infected culture demise. We used a high-resolution pigment method (Airs et al. 2001), designed specifically to detect Type I (intact macrocycle) chl a transformation products.

\section{MATERIALS AND METHODS}

\section{Cultures and experimental design}

Axenic cultures of Emiliania huxleyi CCMP 1516 from the Plymouth Marine Laboratory culture collection were grown in batch in ultra-filtered seawater medium enriched with f/2 nutrients (Guillard 1975). Cultures were maintained at $16^{\circ} \mathrm{C}$ with a light:dark cycle of $12: 12 \mathrm{~h}$, and prior to experiments were kept in mid-exponential growth phase by transferring 5 to $10 \%(\mathrm{v} / \mathrm{v})$ E. huxleyi culture to fresh f/2 media. Six replicate 6.51 cultures were set up in 101 polycarbonate carboys, and samples were aseptically withdrawn from each culture daily at approximately 09:00 $\mathrm{h}$ for the determination of cell abundance using a FACScan flow cytometer (Becton Dickinson) equipped with a $15 \mathrm{~mW}$ laser exciting at $488 \mathrm{~nm}$ with a standard filter set up (Marie et al. 1999). After $5 \mathrm{~d}$ of growth, viral lysate (EhV86, 0.29 l) was added to 3 of the cultures at a virus to cell ratio of approximately 0.1 , while sterile $\mathrm{f} / 2$ medium (0.29 1) was added to the remaining 3 control cultures. The low ratio of viruses to host cells was required to allow the infection to proceed at a rate slow enough for the control cultures to reach stationary phase within the time frame of the experiment. This was necessary so that the transformation products detected in the infected cultures could be compared with those produced during stationary phase growth rather than exponential growth, comparable with natural environment bloom decline rather than bloom formation. Virus enumeration was conducted using the flow cytometric protocol of Brussaard (2004): $1 \mathrm{ml}$ samples were fixed in $0.5 \%$ (final concentration) glutaraldehyde for $30 \mathrm{~min}$ at $4{ }^{\circ} \mathrm{C}$, flash frozen in liquid nitrogen and stored at $-80^{\circ} \mathrm{C}$ until analysis. Fixed frozen samples were subsequently thawed, and aliquots $(10 \mu \mathrm{l})$ were combined with SYBR Green I nucleic acid gel stain (10 $\mu \mathrm{l})$ and TE buffer $\left(980 \mu \mathrm{l}, 10 \mathrm{mM}\right.$ Tris- $\mathrm{HCl}_{i} 1 \mathrm{mM}$ EDTA, $\mathrm{pH}$ 8). The stained samples were incubated at $80^{\circ} \mathrm{C}$ for $10 \mathrm{~min}$ in the dark and then cooled at room temperature for $5 \mathrm{~min}$ before flow cytometric analysis (FACScan flow cytometer). All flow cytometry files were analysed using WinMDI 2.8 software (J. Trotter, http://facs.scripps.edu).

\section{Analysis of chl $a$ and its transformation products}

At 5 sampling points the culture vessels were gently swirled by hand to ensure that the cultures were well mixed before aseptically withdrawing 1 to 21 of culture for analysis by high performance liquid chromatography mass spectrometry (HPLC-MS). These samples were vacuum-filtered through multiple $47 \mathrm{~mm}$ diameter Whatman GF/F filters (Sigma Aldrich; $200 \mathrm{ml}$ per filter). The GF/F filters were extracted in acetone $(100 \%)$ following the method described by Bale et al. (2011). These extracts were analysed by reversed phase HPLC using a highresolution method designed to detect pigments and Type I chl a transformation products, as described by Airs et al. (2001) on the HPLC-MS system and column described by Bale et al. (2011). Extracts were prepared for injection in the autosampler using an automated mixing program (90:10 sample:Milli-Q water). LC-MS was performed using an Agilent Technologies 1200 Series system comprising a G1367 B autosampler, G1312 A binary pump, G1315 B diode array detector and a 6330 Ion Trap equipped with an atmospheric pressure chemical ionization source operated in positive ion mode. Interface settings were: drying gas temperature $350^{\circ} \mathrm{C}$, vaporizer temperature $450^{\circ} \mathrm{C}$, nebulizer 60 psi and drying gas $5 \mathrm{l}$ $\mathrm{min}^{-1}$. Compound quantification was carried out as described by Bale et al. (2011).

\section{RESULTS AND DISCUSSION}

\section{Cell growth and viral dynamics}

After inoculation with the stock culture on Day 1, there was an initial lag phase of approximately $24 \mathrm{~h}$ before all 6 replicate cultures grew at an average net growth rate of $0.5 \mathrm{~d}^{-1}$, between Days 2 and 5 (Fig. 1),

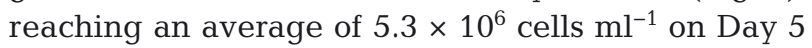
when the cultures entered stationary growth phase. There was a further increase in cell numbers in all cultures between Days 8 and 10, but the effect of viral infection was apparent by Day 10 when maximum average Emiliania huxleyi density in the control cultures was significantly higher than in the infected treatments (2-sample $t$-test, $\mathrm{p}=0.017) ; 7.5 \times$ $10^{6}$ and $6.2 \times 10^{6}$ cells ml $^{-1}$, respectively (Fig. 1). After this point, E. huxleyi cell density in the control cultures remained constant for $2 \mathrm{~d}$ and then began to decline, while cell density in the infected cultures decreased immediately, concomitant with an increase in EhV86. Despite the decline in cell density 


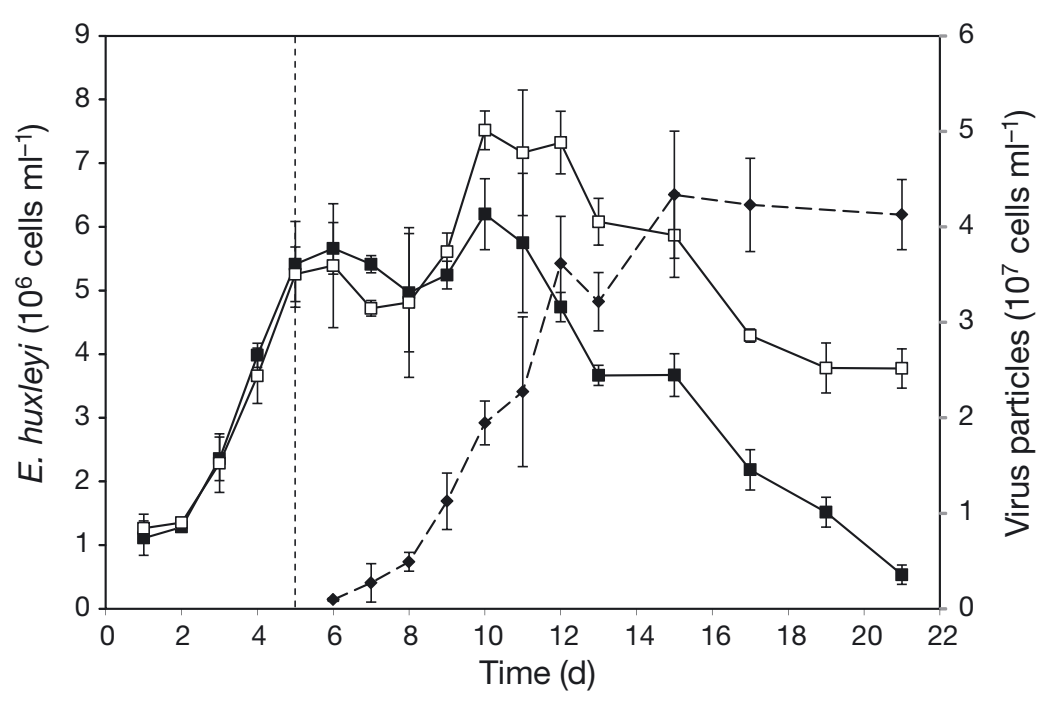

Fig. 1. Emiliania huxleyi. Time series of cells in infected cultures (घ) and non-infected control cultures ( $\square$ ) and of EhV86 virus particle counts $(\diamond)$. Dashed vertical line indicates point of infection. Error bars show $\pm 1 \mathrm{SD}$

$$
(\mathrm{n}=3)
$$

in the controls in the later stages of the experiment, it was consistently higher compared to the infected cultures (Fig. 1). Virus particles (EhV86) reached a maximum average of $4.3 \times 10^{7}$ particles $\mathrm{ml}^{-1}$ on Day 15 , and then declined slightly to a final average of $4.1 \times$ $10^{7}$ particles $\mathrm{ml}^{-1}$ on Day 21 (Fig. 1). The initially low ratio of virus particles to cells $(\sim 0.1)$ would most probably have led to several cycles of infection and particle release between Days 5 and 10, which delayed the onset of population decline and gave the control cultures time to reach stationary phase. Axenic stock cultures and axenic media were used for inoculation. While we did not carry out counts of bacterial numbers, bacterial contamination was minimized through established axenic culturing and sampling techniques. All cultures were from the same stock; if there were greater bacterial numbers in the virus-infected cultures then this would have been related to the process of viral infection.

\section{Type I chl a transformation products}

Assignments of chl $a$, its C-13 ${ }^{2}$ diasteroemer (chl $\left.a^{\prime}\right)$ and phytin a were made by comparison of their ultraviolet-visible (UV-vis) spectra (Table 1) with published data (Jeffrey \& Vesk 1997) in conjunction with protonated molecule data (Airs et al. 2001). Three components were identified as chlorins from their UV-vis spectra but did not correspond to commonly reported Type I ch a transformation products. HPLC-MS analysis was used to assign structures, where possible, to these compounds (Table 1). Components 1 and 3 both exhibited UV-vis and mass spectra (Table 1) identical to components detected previously in cultures of Isochrysis galbana and Pavolova gyrans (Bale et al. 2011). During LC-MS, both exhibited a signal at a specific mass to charge ratio (m/z) of 909, corresponding to $[\mathrm{M}+\mathrm{H}]^{+}$(the protonated molecule) of $13^{2}$-hydroxy-chl a. Resonanceinduced excitation of $\mathrm{m} / \mathrm{z} 909$ in component 3 resulted in a dominant ion at $\mathrm{m} / \mathrm{z} 631\left([\mathrm{M}+\mathrm{H}]^{+}-278 \mathrm{Da}\right)$, which was consistent with a loss of the phytyl chain as phytadiene and hence component 3 was identified as $13^{2}$-hydroxy-chl a. Component 1 was previously assigned as $13^{2}$-hydroxy-chl-a-like due to insufficient signal intensity to carry out $\mathrm{MS}^{2}$ (tandem mass spectrometry) and its earlier elution relative to $13^{2}$-hydroxy-chl a (Bale et al. 2011). In the present study, $\mathrm{MS}^{2}$ was possible, and interestingly the dominant ion in the spectrum arising from m/z 909 in component 1 was that at m/z $849\left([\mathrm{M}+\mathrm{H}]^{+}-60 \mathrm{Da}\right)$, consistent with loss of a carbomethoxy substituent with hydrogen transfer. Lower intensity ions were present at $\mathrm{m} / \mathrm{z} 631\left([\mathrm{M}+\mathrm{H}]^{+}-278 \mathrm{Da}\right)$ and $\mathrm{m} / \mathrm{z} 630\left([\mathrm{M}+\mathrm{H}]^{+}-\right.$ $279 \mathrm{Da})$. These result from the loss of phytyl as phytadiene with and without proton transfer back to the

Table 1. Assignments of chlorophyll a ( $\mathrm{chl} \mathrm{a}$ ) and its Type I transformation products. Ultraviolet-visible (UV-vis) absorption bands were determined on-line during analysis so the solvent mixture corresponds to the HPLC gradient composition at the time point of elution. $13^{2}$-hydroxy-chl $a^{\prime}$ : C-13 $3^{2}$ diastereomer of $13^{2}$-hydroxy-chl $a_{i}$ $\mathrm{C}_{422,656}$ : unknown chlorin; Chl $a^{\prime}$ : C- $13^{2}$ diastereomer of chl $a_{\text {; }}$ Phytin $a$ : phaeophytin $a$

\begin{tabular}{|c|c|c|c|c|c|}
\hline $\begin{array}{l}\text { Component } \\
\text { number }\end{array}$ & $\begin{array}{l}\text { Reten- } \\
\text { tion time } \\
\text { (min) }\end{array}$ & $\begin{array}{l}\text { Main UV-vis } \\
\text { absorption } \\
\text { bands (nm) }\end{array}$ & Assignment & $\begin{array}{c}{[\mathrm{M}+\mathrm{H}]^{+}} \\
(\mathrm{m} / \mathrm{z})\end{array}$ & $\begin{array}{l}\text { Prominent } \\
\text { fragment } \\
\text { ions }(\mathrm{m} / \mathrm{z})\end{array}$ \\
\hline 1 & 31.6 & $432,664 \quad 1$ & $13^{2}$-hydroxy-chl $a^{\prime}$ & $q^{\prime} \quad 909$ & $850,631,630$ \\
\hline 2 & 37.8 & 422,656 & $\mathrm{C}_{422,656}$ & & \\
\hline 3 & 39.5 & $432,664 \quad 1$ & $13^{2}$-hydroxy-chl a & a 909 & $851,631,558$ \\
\hline 4 & 44.1 & 432,664 & Chl a & 893 & $833,615,583,555$ \\
\hline 5 & 46.8 & 434,668 & Chl $a^{\prime}$ & 893 & $834,615,583,555$ \\
\hline 6 & 64.9 & 410,666 & Phytin a & 871 & $839,593,533$ \\
\hline
\end{tabular}


macrocycle, respectively. A difference in stereochemistry at $\mathrm{C} 13^{2}$ or $\mathrm{C} 17$ could be the reason that loss of the phytyl chain is less favourable for component 1 than component 3. Component 1 was assigned as the $\mathrm{C}-13^{2}$ diastereomer of $13^{2}$-hydroxy-chl $a$ and is hence described as $13^{2}$-hydroxy-chl $a^{\prime}$. While the $[\mathrm{M}+\mathrm{H}]^{+}$ion for component 2 could not be established, its retention time and UV-vis spectrum (Table 1) also corresponded to a component thought to be an oxidative transformation product of chl a which had previously been detected in our laboratory (Bale et al. 2011) and was assigned as $C_{422,656}$.

From Day 8 onwards, the average concentration of chl a per cell for both the infected and control cultures declined overall and followed a noticeably similar trend in both sets of cultures (Fig. 2a). There was also
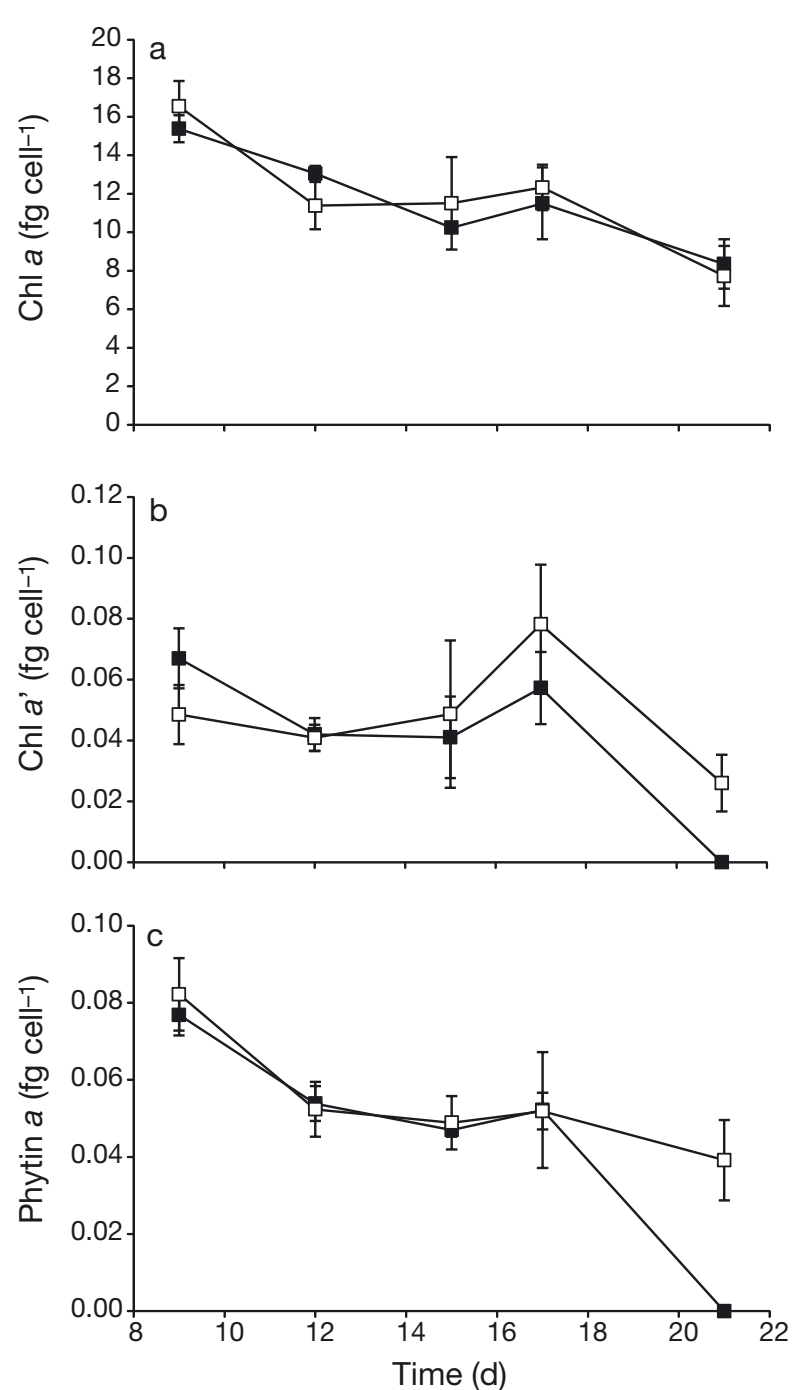

no significant difference between the infected and uninfected cultures in the cellular concentrations of chl $a^{\prime}$ and phytin $a$, although neither chl $a^{\prime}$ nor phytin $a$ could be detected in the infected cultures at the final time point (Fig. 2b,c). This indicates that these transformation products, which have been applied as biomarkers for fate of phytoplankton cell demise in the natural environment (e.g. Head \& Horne 1993, Chen et al. 2003, Walker \& Keely 2004), are not indicators of viral infection in Emiliania huxleyi 1516. The cellular concentration of $13^{2}$-hydroxy-chl a', $\mathrm{C}_{422,656}$ and $13^{2}$-hydroxy-chl-a all followed similar trends to each other: they remained constant throughout the experiment in the control cultures, while in the infected cultures they increased throughout the experiment but most noticeably between the 2 final sam-
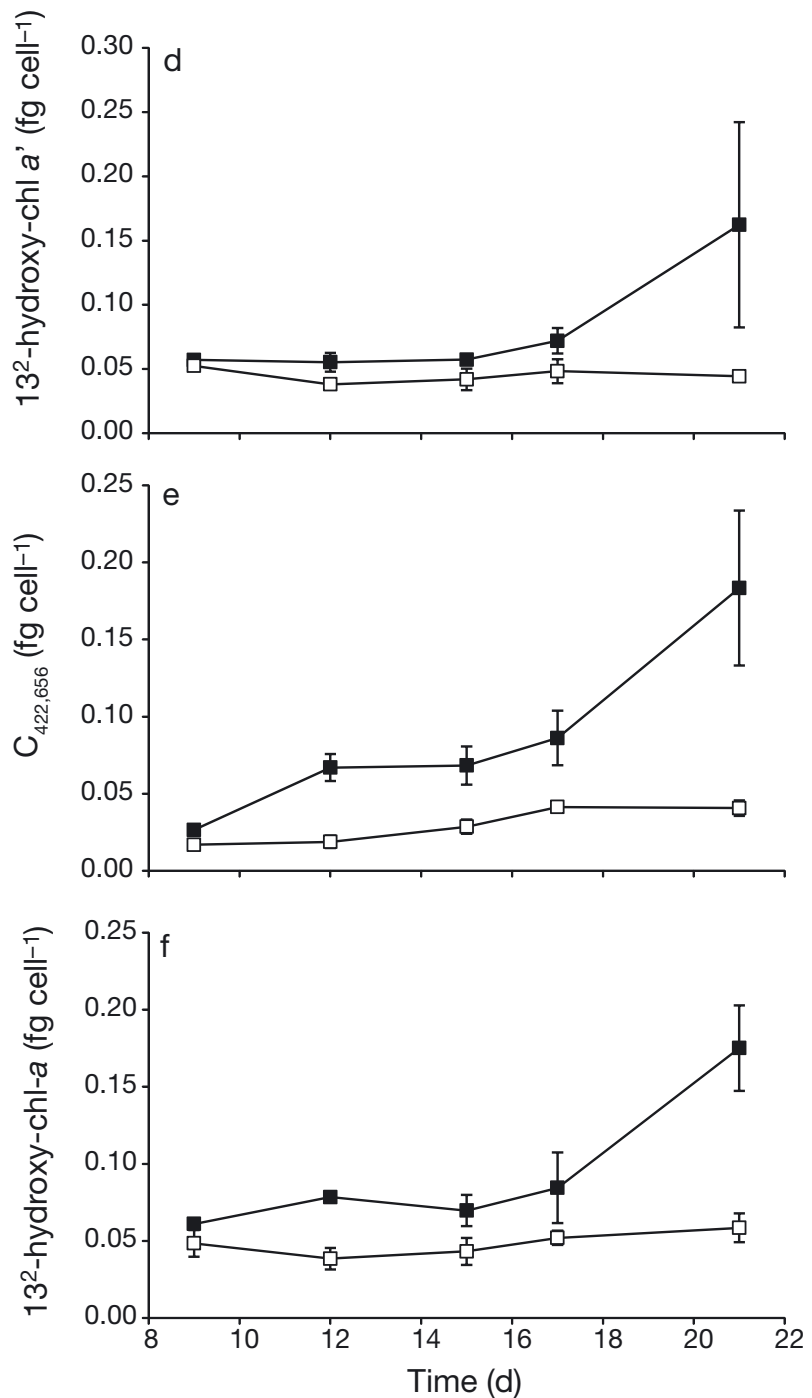

Fig. 2. Emiliania huxleyi. Concentration of (a) chlorophyll a (chl a), (b) the C-132 diastereomer of chl a (chl a'), (c) phaeophytin a (phytin a), (d) $13^{2}$-hydroxy-chl $a^{\prime}$, (e) unknown chlorin, $C_{422,656}$ and (f) $13^{2}$-hydroxy-chl-a. $\mathbf{\square}$ : infected cultures; $\square$ : noninfected control cultures. Error bars show $\pm 1 \mathrm{SD}(\mathrm{n}=3)$ 
pling points (Fig. 2d-f). It is worth noting that the data indicate that viral infection leads to an earlier onset of pigment transformation than in the control cultures. As the most significant differences between the levels of the Type I oxidation products in the infected and control samples occur at $21 \mathrm{~d}$, a possible lag between the infected and control samples should be considered in interpreting the trends. The cell count data suggest that the lag may be around 5 to $6 \mathrm{~d}$. Hence, by Day 26 to 27, it would be possible in this experimental set up that the levels of Type I oxidation products in the control might reach similar concentrations. However, neither the cell ageing study by Franklin et al. (2012) with E. huxleyi cultures (strain CCMP 1516; calcifying) grown through to stationary phase for a month nor a separate experiment from our own laboratory with cultures of E. huxleyi CCMP 1516 aged over 2 mo (N. J. Bale, R. L. Airs, \& C. A. Llewellyn unpubl. results) found relative increases in Type I oxidation products. Overall, these results indicate that allomerization, known to be a preliminary reaction in chl a breakdown (Brown et al. 1991), was a more dominant chl a transformation process during viral infection than during culture ageing in E. huxleyi.

The intracellular reactive oxygen species (ROS) concentration has been shown to increase during viral infection of Emiliania huxleyi (Evans et al. 2006, Vardi et al. 2012), and other studies have linked increased ROS levels associated with heat stress with increased oxidative transformation of chl a (e.g. Dove et al. 2006). Evans et al. (2006) suggested that it may be the disruption of photosynthesis, in combination with other pathways, which leads to increased ROS production during viral infection. It is possible therefore, that during the present study the increased concentration per cell of the chl a oxidation transformation products may have been the result of increased ROS production in the infected cells. Further experiments would be necessary to confirm this hypothesis. Interestingly, both Evans et al. (2006) and Vardi et al. (2012) noted that ROS production in infected E. huxleyi cultures became most significant at the latter stages of the culture decline. During the present study, there was also a sudden increase in the concentration per cell of all 3 Type I oxidative products over chl $a$ at a late stage of the culture decline, $11 \mathrm{~d}$ after the cell numbers began to decline.

There are 2 distinct mechanisms of chl a oxidation: reaction with singlet oxygen at position $\mathrm{C}-5$, generating Type II products with cleaved macrocycles (Mühlecker et al. 1993); or reaction with molecular oxygen (triplet oxygen), which leads to Type I products which have an intact macrocycle with oxygen incorporated around ring E (Hynninen 1991). Whether Type I oxidation products are formed as intermediates during Type II destruction of chl $a$ is still not fully understood (Hynninen et al. 2010). During our study, the summed concentration of $\mathrm{chl} a$ and its Type I products decreased by $94 \%$ (infected cultures, data not shown), suggesting that the vast majority of the chl a breakdown must have occurred by Type II transformation to colourless products. Using the HPLC-MS methods described by Bale et al. (2011), we did not detect ring-open Type II degradation products in this experiment.

In a similar study, Llewellyn et al. (2007) postulated that the rapid decline in the carotenoid $\beta, \beta$-carotene that they observed in infected cultures of Emiliania huxleyi may have been a result of its role in scavenging ROS or may have been due to degradation of the photosystems by ROS. Whilst our study focused on chlorophyll transformation products, we were also interested to see how the carotenoid profiles compared to those reported by Llewellyn et al. (2007). The design of the experiments and thus the growth conditions of both the control and virally infected cultures were quite different in the 2 studies: in our study, we looked at viral infection during stationary phase, whereas Llewellyn et al. (2007) studied cells in exponential phase; hence the lower ratio of virus particles to cells used in our study caused a slower rate of infection compared to the results of Llewellyn et al. (2007). Although the differences in experimental design make a direct comparison difficult, some similar trends were observed. In our study, the deepoxidation ratio (diatoxanthin/diadinoxanthin +diatoxanthin) increased during virus infection ( 0.11 to 0.29). Llewellyn et al. (2007) observed a larger increase in the de-epoxidation state of the xanthophyll cycle pigments $(0.15$ to 0.60$)$, likely due to the more rapid infection of cells in that study. The ratio of $\beta, \beta$-carotene to chl $a$ for both infected and control cultures varied between $0.011( \pm 0.004)$ and 0.024 $( \pm 0.003)$, but did not show an overall increase or decrease. These values are within the range reported by Llewellyn et al. (2007), where $\beta, \beta$-carotene declined from 0.03 to below the detection limit in the infected culture and remained constant at 0.03 in the control culture.

\section{CONCLUSIONS}

This experiment with Emiliania huxleyi has provided evidence that viral infection does not lead to increases in the cellular concentrations of chl $a^{\prime}$ or 
phytin a but does lead to increases in cellular concentration of Type I oxidative transformation products of chl $a$, which we hypothesise is due to increased oxidative stress and ROS. Our findings indicate that such chl a oxidation products may be informative in future microbial ecology studies that, for example, examine the role of viral lysis in phytoplankton bloom demise.

Acknowledgements. We thank the Natural Environment Research Council (NERC) for providing a studentship to N.J.B. LC-MS instrumentation was part-funded by the Technology and Strategy Board's Collaborative Research and Development programme and by Plymouth Marine Laboratory. We thank R. Woods for assistance with the Emiliania huxleyi ageing experiment. We also thank C. Brussaard for helpful discussions during the preparation of this manuscript and 3 anonymous reviewers for constructive edits and helpful suggestions.

\section{LITERATURE CITED}

Airs RL, Atkinson JE, Keely BJ (2001) Development and application of a high resolution liquid chromatographic method for the analysis of complex pigment distributions. J Chromatogr A 917:167-177

Bale NJ, Airs RL, Llewellyn CA (2011) Type I and Type II chlorophyll-a transformation products associated with algal senescence. Org Geochem 42:451-464

Baudoux AC, Noordeloos AAM, Veldhuis MJW, Brussaard CPD (2006) Virally induced mortality of Phaeocystis globosa during two spring blooms in temperate coastal waters. Aquat Microb Ecol 44:207-217

Bratbak G, Egge JK, Heldal M (1993) Viral mortality of the marine alga Emiliania huxleyi (Haptophyceae) and termination of algal blooms. Mar Ecol Prog Ser 93:39-48

Brown SB, Houghton JD, Hendry GAF (1991) Chlorophyll breakdown. In: Scheer H (ed) Chlorophylls. CRC Press, Boca Raton, FL, p 339-364

Brussaard CPD (2004) Optimization of procedures for counting viruses by flow cytometry. Appl Environ Microbiol 70:1506-1513

> Chen N, Bianchi TS, Bland JM (2003) Implications for the role of a pre- versus post-depositional transformation of chlorophyll-a in the Lower Mississippi River and Louisiana shelf. Mar Chem 81:37-55

Dove S, Ortiz JC, Enriquez S, Fine M and others (2006) Response of holosymbiont pigments from the scleractinian coral Montipora monasteriata to short-term heat stress. Limnol Oceanogr 51:1149-1158

Editorial responsibility: Curtis Suttle, Vancouver, British Columbia, Canada
Evans C, Malin G, Mills GP, Wilson WH (2006) Viral infection of Emiliania huxleyi (Prymnesiophyceae) leads to elevated production of reactive oxygen species. J Phycol 42:1040-1047

Franklin DJ, Airs RL, Fernandes M, Bell TG, Bongaerts RJ, Berges JA, Malin G (2012) Identification of senescence and death in Emiliania huxleyi and Thalassiosira pseudonana: cell staining, chlorophyll alterations, and dimethylsulfoniopropionate (DMSP) metabolism. Limnol Oceanogr 57:305-317

Guillard RRL (1975) Culture of phytoplankton for feeding marine invertebrates. In: Smith WL, Chanley MH (eds) Culture of marine invertebrate animals. Plenum Press, New York, NY, p 29-60

> Head EJH, Horne EPW (1993) Pigment transformation and vertical flux in an area of convergence in the North Atlantic. Deep-Sea Res II 40:329-346

Hynninen PH (1991) Chemistry of the chlorophylls: modifications. In: Scheer H (ed) Chlorophylls. CRC Press, Boca Raton, FL, p 145-210

Hynninen PH, Kaartinen V, Kolehmainen E (2010) Horseradish peroxidase-catalyzed oxidation of chlorophyll a with hydrogen peroxide: characterization of the products and mechanism of the reaction. Biochim Biophys Acta 1797:531-542

Jeffrey SW, Vesk M (1997) Introduction to marine phytoplankton and their pigment signatures. In: Jeffrey SW, Mantoura RFC, Wright SW (eds) Phytoplankton pigments in oceanography: guidelines to modern methods. UNESCO Publishing, Paris, p 37-84

Llewellyn CA, Evans C, Airs RL, Cook I, Bale N, Wilson WH (2007) The response of carotenoids and chlorophylls during virus infection of Emiliania huxleyi (Prymnesiophyceae). J Exp Mar Biol Ecol 344:101-112

Marie D, Brussaard CPD, Partensky F, Vaulot D (1999) Enumeration of phytoplankton, bacteria and viruses in marine samples. In: Robinson JP, Darzynkiewicz Z, Dean PN, Orfao A and others (eds) Current protocols in cytometry. Wiley, New York, NY, p 11.11.11-11.11.15

Mühlecker W, Kräutler B, Ginsburg S, Matile P (1993) Breakdown of chlorophyll: a tetrapyrrolic chlorophyll catabolite from senescent rape leaves. Helv Chim Acta 76:2976-2980

Short SM (2012) The ecology of viruses that infect eukaryotic algae. Environ Microbiol 14:2253-2271

> Suttle CA (2005) Viruses in the sea. Nature 437:356-361

- Vardi A, Haramaty L, Van Mooy BAS, Fredricks HF, Kimmance SA, Larsen A, Bidle KD (2012) Host-virus dynamics and subcellular controls of cell fate in a natural coccolithophore population. Proc Natl Acad Sci USA 109: 19327-19332

Walker JS, Keely BJ (2004) Distribution and significance of chlorophyll derivatives and oxidation products during the spring phytoplankton bloom in the Celtic Sea April 2002. Org Geochem 35:1289-1298

Submitted: October 21, 2012; Accepted: May 12, 2013

Proofs received from author(s): June 20, 2013 